\title{
Optimization of Delivery Routes using the Little's Algorithm
}

\author{
Rudolf Kampf \\ Institute of Technology and Business in \\ České Budějovice \\ Faculty of Technology, Department of \\ Transport and Logistics, Czech Republic \\ e-mail:kampf@mail.vstecb.cz
}

DOI 10.17818/NM/2018/4SI.13

UDK 656.01

Preliminary communication

Paper accepted: 28. 8. 2018.

\section{Summary}

The contribution focuses on possible use of operational research methods in practice. The application of operational research methods is made on a specific transport relation, which is used by the LOGI company for the product distribution. Optimization of the delivery route was carried out using the Little's law. The optimization resulted in a total saving of $312 \mathrm{~km}$ per year.

\section{KEY WORDS}

Little's law

transport

transport problems

operational research

\section{INTRODUCTION}

The contribution shows a part of a project processed for the LOGI production company (the company name has been changed due to the protection of the sensitive data). The project deals with optimizing the existing distribution network of the given company.

The aim of the contribution is to show the possibility of operational research methods application in practice. The application refers to a specific transport relation, which is used by the LOGI company for the distribution of its products. Optimization measures which lead to the more efficient transport routes at the LOGI company will be proposed. .

Operational research can be a significant support to business entities in the decision-making process in the field of organizing transport and provides many methods applicable in optimizing distribution routes.

For the purposes of this article, a distribution route with a total length of $231 \mathrm{~km}$ was chosen. The route contains seven delivery points listed in Table 1. The circuit starts in Hradec Králové, where the goods are loaded. Subsequently all customers will be served in the predefined order and then the goods are returned back to the company. The objective is to reduce the kilometres travelled and to serve all delivery points.

\begin{tabular}{|c|c|c|}
\hline \multicolumn{3}{|c|}{ Original route } \\
\hline Order & Delivery points & $\mathrm{Km}$ \\
\hline 0. & Hradec Králové & 0 \\
\hline 1. & Česká Třebová & 64 \\
\hline 2. & Litomyšl & 12 \\
\hline 3. & Svitavy & 19 \\
\hline 4. & Polička & 17 \\
\hline 5. & Nové Město na Moravě & 27 \\
\hline 6. & Chrudim & 59 \\
\hline \multirow[t]{2}{*}{7.} & Hradec Králové & 33 \\
\hline & In total & 231 \\
\hline
\end{tabular}

\section{METHODS}

To solve the research task, Little's law (method) was selected as one of the operational research methods that will enable the optimization of the distribution routes.

The calculation will be made in the table of entries distance matrix in kilometres $(\mathrm{km})$ rounded to whole numbers for each pair of points. After applying the above mentioned mathematical and economical methods, new order of points on the distribution routes will be obtained. The final solution will be compared with the deliveries executed so far in order to compare the number of the kilometres travelled [1,2].

Little's law is based on the application of branch and bound approach, in which a set of permissible solutions is systematically reduced until an optimal solution is found. The problem can be expressed by symmetric or asymmetric square matrix, where the individual matrix elements represent a specific characteristic, such as the distance between the customers.

In the matrix, two types of routes are excluded one by one [5]: Route back and forth from the $\mathrm{i}-$ point, that is, all the fields on the main diagonal of the default matrix. Those routes, considered forbidden, are marked with " $\mathrm{X}$ ",

Routes leading to premature closure of the circuit, that is, its closing before all planned points are included. For this reason, the routes are considered forbidden and marked

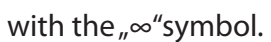

Description of the Little's algorithm $[5,7,8]$ :

First, the square matrix with crossed-out fields on the main diagonal will be reduced by subtracting the lowest entries (socalled transformation constants $\alpha$ and $\beta$ ) from each column and row of the matrix found in the relevant column and row so that there is at least one zero entry $\left(c_{i j}=0\right)$ in each row,

1. Calculation of the $Z 0=$ lower limit (root of the tree) value, by which the value of the real function will be lowered after the reduction of the matrix:

$$
Z_{0}=\sum_{i=1}^{n} \alpha_{i}+\sum_{j=1}^{n} \beta_{j}
$$


where $\alpha_{i}$ and $\beta_{j}$ are transformation constants for $\mathrm{i}-$ row and $j$ - column $(i=j=1,2, \ldots, n)$,

2. Calculation of the $\Phi_{i j}=$ zero entries evaluation value, for all the fields with a reduced zero entry $\left(c_{i j}=0\right)$ :

$$
\Phi i j=\min c_{i}^{*}+\min c_{j}^{*}
$$

where $\min c_{i}^{*}$ and $\min c_{j}^{*}$ are the lowest reduced distances in $\mathrm{i}-$ row and $\mathrm{j}$ - column,

3. Finding $\Phi_{i j}=\Phi_{\text {max }^{\prime}}$ which determined the allocation of the route from the $i$ - to $j$-point in the circuit (if there are more $\Phi_{\max }$, it is possible to choose for any of these routes),

4. If a distance from $\mathrm{i}$ - to $\mathbf{j}$ - point in the circuit is not included, the real function value must be calculated:

$$
Z_{\overline{l, j}}=Z_{0}+\Phi \max
$$

5. Omitting $\mathrm{i}$ - row and $\mathrm{j}$ - column of the reduced distance matrix and simultaneous exclusion of the return route (i.e. the route from $j$ - point to $i$ - point) by marking the relevant field of the "forbidden" route with the " $\infty$ "symbol,

6. Verification if there is at least one zero entry cij $=0$ in each row and each column of the reduced matrix (if there is not another reduction of distances must be carried out using new transformation constants as in the point 1 ),

7. Verification of correctness of the classification of the route from i-point to j-point using $Z_{i, j} \leq Z_{\bar{l}, j}$ where $Z_{i, j}$ is the value of the previous real function enlarged by $\sum_{i=1}^{n} \alpha_{i}+\sum_{j=1}^{n} \beta_{j}$ , where the transformation constants $\alpha_{i}$ and $\beta_{j}$ have been taken from the point 7. If the relation is not applicable, it is necessary to start anew because the defined algorithm was not strictly observed,

8. Repeat the above mentioned procedure starting from the point 3 till the moment of getting the reduced distance matrix $2 \times 2$, where two out of four routes are considered forbidden, the two remaining routes close the circuit and thus the calculation is over.

\section{APPLICATION OF LITTLE'S LAW}

We work with the basic distance matrix, in this case complemented by a row and a column of the transformation constants $\alpha_{i}$ and $\beta_{j}$, which are used for the reduction of the matrix $[3,6,7,8]$. The content of these fields are the row and column minima, which will be gradually subtracted so that there is at least one zero entry in each row and column. The sum of all subtracted minima indicates the lower limit $Z_{0}$ $(12+33+33+12+27+17+17+10=161)$, when the length of the route cannot be less than $161 \mathrm{~km}$ (Table 2 ).

Table 2 Matrix A

\begin{tabular}{|c|c|c|c|c|c|c|c|c|c|}
\hline A & & 1 & 2 & 3 & 4 & 5 & 6 & 7 & $a_{i}$ \\
\hline 1 & ČT & X & 64 & 53 & 12 & 57 & 31 & 22 & 12 \\
\hline 2 & HK & 64 & X & 33 & 55 & 89 & 72 & 73 & 33 \\
\hline 3 & Chr & 53 & 33 & X & 44 & 59 & 50 & 63 & 33 \\
\hline 4 & Lit & 12 & 55 & 44 & $X$ & 46 & 20 & 19 & 12 \\
\hline 5 & NMnM & 57 & 89 & 59 & 46 & $X$ & 27 & 43 & 27 \\
\hline 6 & Po & 31 & 72 & 50 & 20 & 27 & $X$ & 17 & 17 \\
\hline 7 & SY & 22 & 73 & 63 & 19 & 43 & 17 & X & 17 \\
\hline$\beta_{j}$ & & 0 & 0 & 0 & 0 & 10 & 0 & 0 & 161 \\
\hline
\end{tabular}

The $A_{1}$ matrix created (Table 2) contains 0 in each row and column, which will be evaluated by the sum of the minimum elements for each row and each column $(22+32=54)$. The zero entry which we are currently evaluating is not counted, while any other " 0 " in the relevant row or column is. We will choose a zero field with the maximum value $\left(0^{54}\right)$. This position determines the criterion by which the division into two branches is executed, and the second row and third column will be dropped from the matrix (Table 3).

Table 3 Matrix $\mathrm{A}_{1}$

\begin{tabular}{|c|c|c|c|c|c|c|c|}
\hline $\mathrm{A}_{1}$ & 1 & 2 & 3 & 4 & 5 & 6 & 7 \\
\hline 1 & $\mathrm{X}$ & 52 & 41 & $0^{12}$ & 35 & 18 & 10 \\
\hline 2 & 31 & $\mathrm{X}$ & $0^{54}$ & 22 & 46 & 39 & 40 \\
\hline 3 & 20 & $0^{54}$ & $\mathrm{X}$ & 11 & 16 & 17 & 30 \\
\hline 4 & $0^{12}$ & 43 & 32 & $\mathrm{X}$ & 24 & 8 & 7 \\
\hline 5 & 30 & 62 & 32 & 19 & $\mathrm{X}$ & $0^{16}$ & 16 \\
\hline 6 & 14 & 55 & 33 & 3 & $0^{16}$ & $\mathrm{X}$ & $0^{7}$ \\
\hline 7 & 5 & 56 & 46 & 2 & 16 & $0^{2}$ & $\mathrm{X}$ \\
\hline
\end{tabular}

Verification:

- The alternative of "left" branch does not consider inclusion of the $\mathrm{Z}_{\overline{2,3}}(\mathrm{ZO}+54=215)$ edge,

- The alternative of the "right" branch considers inclusion of the $Z_{2,3}$ edge of the $A 2$ matrix modified by the sum of other row and column minima reacquire zero values under the condition that the $Z_{3,2}$ route from the opposite direction will be forbidden and marked with " $\infty$ " $\left(\mathrm{Z}_{0}+11+43=215\right)$,

- Fulfilling the $Z_{\overline{2,3}} \geq Z_{2,3}$ condition. Inclusion of the $Z_{2,3}$ edge into the route is thus considered.

Next, the same calculation is carried out until obtaining modified matrix A8 (Table 4) on the basis of the above mentioned procedures. After excluding the counter route $Z_{4,1}$ , and at the same time excluding the $Z_{7,2}$ route, which would lead to the premature closure of the circuit (this is marked with the " $\infty$ " symbol), only one possible connection of $Z_{7,1}$ and $Z_{4,2}$ remains. This way the circuit is closed and all the points are served (Table 5).

\begin{tabular}{|c|c|c|c|}
\multicolumn{5}{|c|}{ Table 4 Matrix $A_{8}$} \\
\hline$A_{8}$ & 1 & 2 & $a_{i}$ \\
\hline 4 & $\infty$ & $0^{\infty}$ & 0 \\
\hline 7 & 3 & 11 & 3 \\
\hline$\beta_{j}$ & 0 & 0 & 0 \\
\hline
\end{tabular}

Table 5 Matrix $\mathrm{A}_{9}$

\begin{tabular}{|c|c|c|c|}
\hline$A_{9}$ & 1 & 2 & $a_{i}$ \\
\hline 4 & $\infty$ & $0^{\infty}$ & 0 \\
\hline 7 & $0^{\infty}$ & $\infty$ & 0 \\
\hline$\beta_{j}$ & 0 & 0 & 0 \\
\hline
\end{tabular}

The application of the Little's algorithm led to the modification of the distribution route and the reduction of its length to $225 \mathrm{~km}$. The order of the points served was modified according to the Table 6 . 
Table 6 Route 1

\begin{tabular}{|c|c|c|}
\hline \multicolumn{3}{|c|}{ Optimized } \\
\hline Order & Distribution points & $\mathrm{Km}$ \\
\hline 0. & Hradec Králové & 0 \\
\hline 1. & Chrudim & 33 \\
\hline 2. & Nové Město na Moravě & 59 \\
\hline 3. & Polička & 27 \\
\hline 4. & Svitavy & 17 \\
\hline 5. & Česká Třbová & 22 \\
\hline 6. & Litomyšl & 12 \\
\hline 7. & Hradec Králové & 55 \\
\hline & In total & 225 \\
\hline
\end{tabular}

\section{CONCLUSION}

The objective of the contribution was to show the possibility of using the operational research methods in practice. The application was carried out on the specific transport RELACl, which is used by the LOGI company for the distribution of its products [12].

By comparing the kilometres travelled before the optimization (see Table 1) and after the optimization (see Table 6 ), it is possible to calculate that after the application of the Little's Law, there was a total saving of $6 \mathrm{~km}$ per one circuit route.

Regarding regular deliveries (once a week), the total saving will be $312 \mathrm{~km}$ per year (52 week x $6 \mathrm{~km}$ ). In the context of the above mentioned, it can be stated that the objective of the contribution has been fulfilled.

\section{REFERENCES}

[1] Andrejiová, M.; Pavlisková, A.; Husáková, N. Application of multi-criterion decision methods by the selection of optimal constructive elements for devices of continuous transport, in: Congr. Proc. - CLC 2012 Carpathian Logist. Congr. 2012: pp. 283-289. http://www.scopus.com/inward/record.url?eid=2-s2.084926216565\&partnerID=40\&md5=6faccdcafe5c2d398cd1e4fd32a5b64c.

[2] Bartuška, L; Biba, V; Kampf, R. Modeling of Dayly Traffic Volumes on Urban Roads, In: Proceedings of the Third International Conference on Traffic and Transport Engineering (ICTTE), 2016, pp. 300-304

[3] Brumercik, F; Krzywonos, L: 2013. Integrated transportation system simulation. In: Logi - Scientific Journal on Transport and Logistics. Vol. 4, No. 2, pp. 5 - 10, ISSN 1804-3216.

[4] Bukova, B; Brumercikova, E Kolarovszki, P.: 2004. Spedition and Logistics (In Slovak). Wolters Kluwer. ISBN 978-80-9168-074-8.

[5] Čejka, J. Transport Planning Realized Through the Optimization Methods, Procedia Engineering, Vol. 161, 2016, pp. 1187-1196 https://doi.org/10.1016/j. proeng.2016.08.538

[6] Chen, $\mathrm{KH}_{i} \mathrm{Lin}, \mathrm{CH}_{;} \mathrm{Chu}_{\mathrm{T}} \mathrm{TH}_{;}$Huang, $\mathrm{KC}$; Jiang, JC. Based on SCOR Model to Structure a Defense System of Collaborative Logistics Management. Journal of the chinese society of mechanical engineers, Volume: 29, Issue: 6, Pages: 491-496, Published: DEC 2008, WOS:000262325400007, ISSN: 0257-9731.

[7] Di Matteo, U; Pezzimenti, PM; Garcia, DA. Methodological Proposal for Optimal Location of Emergency Operation Centers through Multi-Criteria Approach. Sustainability, Volume: 8 , Issue: 1, Article Number: 50, Published: JAN 2016, WOS:000372456200050. https://doi.org/10.3390/su8010050

[8] Fedorko, G; Rosová, A; Molnár, V. The application of computer simulation in solving traffic problems in the urban traffic management in Slovakia, Theor. Empir. Res. Urban Manag. 9 (2014) 5-17. http://www.scopus.com/inward/ record.url?eid=2-s2.0-84905402564\&partnerlD=40\&md5=5e50fd2d 1005596 f98da7ffeef9a4291.

[9] Krile, S. Dimensioning of Multiple Capacity Transport Line with Mutua Traffic Correlation. Source: Intelligent transportation systems - problems and perspectives, Book Series: Studies in Systems Decision and Control, Volume: 32, Pages: 127-158, Published: 2016, WOS:000381768100006, ISSN: 2198 4182, ISBN: 978-3-319-19150-8, https://doi.org/10.1007/978-3-319-19150-8

[10] Marasova, D; Andrejiova, M. Transport Service Quality Assessment. Qualityaccess to success, Volume: 19, Issue: 162, Pages: 56-59, Published: FEB 2018 WOS:000423622200004, ISSN: 1582-2559.

[11] Stopka, O.; Sarkan, B; Chovancova, M; Kapustina, L.M. Determination of the appropriate vehicle operating in particular urban traffic conditions (2017) Communications - Scientific Letters of the University of Zilina, 19 (2), pp. 18 22. ISSN: 13354205

[12] Torok, A. Comparative Analysis Between the Theories of Road Transport Safety and Emission. Transport, Volume: 32, Issue: 2, Pages: 192-197, Published: 2017 WOS:000402521700008. https://doi.org/10.3846/16484142.2015.1062798 